\title{
Exploring the perceptions of Grade 5 learners about the use of videos and PowerPoint presentations when learning fractions in mathematics
}

\begin{tabular}{|c|c|}
\hline \multicolumn{2}{|c|}{$\begin{array}{l}\text { Authors: } \\
\text { Jayaluxmi Naidoo }{ }^{1} \\
\text { Shamilla Hajaree }\end{array}$} \\
\hline \multicolumn{2}{|c|}{ 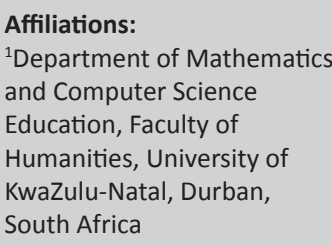 } \\
\hline \multicolumn{2}{|c|}{$\begin{array}{l}{ }^{2} \text { KwaDukuza Primary School, } \\
\text { Stanger, KwaDukuza, } \\
\text { South Africa }\end{array}$} \\
\hline \multicolumn{2}{|c|}{$\begin{array}{l}\text { Corresponding author: } \\
\text { Jayaluxmi Naidoo, } \\
\text { naidooj2@ukzn.ac.za }\end{array}$} \\
\hline \multicolumn{2}{|c|}{$\begin{array}{l}\text { Dates: } \\
\text { Received: } 12 \text { Feb. } 2020 \\
\text { Accepted: } 15 \text { Nov. } 2020 \\
\text { Published: } 25 \text { Jan. } 2021\end{array}$} \\
\hline \multicolumn{2}{|c|}{$\begin{array}{l}\text { How to cite this article: } \\
\text { Naidoo, J. \& Hajaree, S., } \\
2021 \text {, 'Exploring the } \\
\text { perceptions of Grade } 5 \\
\text { learners about the use of } \\
\text { videos and PowerPoint } \\
\text { presentations when learning } \\
\text { fractions in mathematics', } \\
\text { South African Journal of } \\
\text { Childhood Education } \\
11(1) \text {, a846. https://doi. } \\
\text { org/10.4102/sajce.v11i1.846 }\end{array}$} \\
\hline \multicolumn{2}{|c|}{$\begin{array}{l}\text { Copyright: } \\
\text { (C) 2021. The Authors. } \\
\text { Licensee: AOSIS. This } \\
\text { is licensed under the } \\
\text { Creative Commons } \\
\text { Attribution License. }\end{array}$} \\
\hline \multicolumn{2}{|l|}{ Read online: } \\
\hline 回安回 & $\begin{array}{l}\text { Scan this QR } \\
\text { code with your } \\
\text { smart phone or } \\
\text { mobile device } \\
\text { to read online. }\end{array}$ \\
\hline
\end{tabular}

Background: Within the ambit of the Fourth Industrial Revolution (4IR), the use of technology-based tools within teaching and learning is advancing rapidly at education institutions globally, including the teaching and learning of mathematics. Learners and teachers have challenges with teaching and learning fractions in mathematics. A learner's understanding of fractions is fundamental for the understanding of key concepts in other mathematics sections.

Aim: This qualitative, interpretive study examined the perceptions of Grade 5 learners about the use of technology-based tools, more specifically videos and PowerPoint presentations when learning fractions in mathematics.

Setting: This study was located at one primary school in KwaZulu-Natal, South Africa.

Methods: The study was framed within the ambit of social constructivism, and data were generated via task-based worksheets, interactive technology-based lessons and focus group interviews.

Results: Based on the results of this study, it was evident that the participants valued the use of the technology-based tools during the teaching and learning of fractions. Based on an interpretive analysis of the data generated, two major themes emerged. Participants indicated that using videos and PowerPoint presentations inspired an appealing and fun way of learning fractions and inspired an encouraging atmosphere for learning fractions. These results may be of value to teachers, teacher educators, researchers, curriculum developers and learners of mathematics.

Conclusion: The concluding comments of this article mention research implications and recommendations for further research within this area. These recommendations are significant as there is a need for educational institutions globally to embrace the 4IR within teaching and learning.

Keywords: Fourth Industrial Revolution; fractions; learning; mathematics; perceptions; PowerPoint presentations; teaching; technology-based tools; videos.

\section{Introduction}

Mathematics is taught at schools to equip learners with mathematical knowledge to develop their problem-solving, communication, critical and systematic thinking skills (Lin \& Rosli 2017). Mathematics is an abstract, conceptual subject (Pope \& Mayorga 2019), and there has been a worldwide decline in interest and achievement in mathematics with young learners (Riley et al. 2017). Using technology-based tools, the understanding of complex and abstract mathematical ideas may be made more achievable for learners (Kaplan \& Alon 2013). Furthermore, the use of technology-based tools in the mathematics classroom may assist learners who are successful, as well as learners who are struggling with mathematics (Bruce 2012). Moreover, within the era of the Fourth Industrial Revolution (4IR), the use of technology-based tools within teaching and learning is an innovative pedagogy to consider. Information and communications technology (ICT) plays an important role in various social sectors within the era in which we live (Chen 2015). Technology has been incorporated into the lifestyles of families for employment, entertainment and communication. This research study extends the use of technology further by incorporating technology-based tools into the classroom to support the teaching and learning of fractions in Grade 5. 
The use of technology-based tools within the classroom also increases learners' motivation and enhances the enjoyment of learning mathematics (Tobin \& Weiss 2016). Increasing learners' motivation and enhancing enjoyment in mathematics can lead to improved performance in mathematics. Attaining improved learner performance in mathematics is important as performance in mathematics at school level in South Africa is low (Spangenberg 2017). South African learners have performed poorly in international studies; for example, South Africa ranked number 47 out of the 48 countries, which participated in the 2015 Trends in International Mathematics and Science Study (TIMSS) (Mullis, Martin \& Sainsbury 2015). Furthermore, Wijaya (2017) noted that of the 13 test items in the TIMSS 2015, eight items addressed basic concepts of fractions, and five items were about operations involving fractions. Thus, it is important to conduct research in South Africa, focussing on the teaching and learning of fractions in mathematics. Within the ambit of the 4IR, it is important to focus on the use of technologybased tools when teaching and learning. Hence, this research study sought to respond to the question: What are Grade 5 learners' perceptions of the use of technology-based tools (i.e. videos and PowerPoint presentations) when learning fractions in mathematics?

\section{Learning fractions in mathematics}

The concept of fractions is one of the aspects of mathematics that many learners find difficult. Sherman, Richardson and Yard (2019) illustrate this point further by elaborating that rational numbers are sometimes challenging for learners who were successful with whole numbers in the early grades. Furthermore, Fennell and Karp (2017) reiterated that proficiency with fractions serves as a prerequisite for learner success in higher-level mathematics, which also serves as a gateway to many careers and varied contexts beyond the mathematics classroom. The concept of fractions is not simple, and the uniqueness of fractions sometimes makes it difficult for learners to understand (Kurniawan et al. 2018). This study focussed on the following concepts within fractions: counting forwards and backwards in fractions, addition and subtraction of fractions with mixed numbers, fractions involving whole numbers, solving problems in real-world contexts involving common fractions, and recognising and using equivalent forms of common fractions with denominators, which are multiples of each other. These were concepts that ought to be taught in the Grade 5 curriculum as stipulated by the General Education and Training (GET) Curriculum and Assessment Policy Statement (CAPS) (Department of Basic Education 2011). The GET band within the South African schooling system encompasses learners from Grades 4 to 9. The CAPS document is an essential document introduced by the South African Department of Basic Education. This document is compulsory for all South African teachers to adhere to in preparation for teaching and learning in all subjects from Grade $\mathrm{R}$ to 12.

Fractions play an important role in the teaching and learning of mathematics (Siegler et al. 2013). However, Simon et al.
(2018) have indicated that promoting a deep understanding of the concept of fractions continues to be a challenge for both teachers and learners. Moreover, learners who have limited foundational knowledge concerning solving problems involving concepts of fractions have challenges with the understanding of advanced concepts within fractions (Loc, Tong \& Chau 2017). Also, a deep understanding of fractions is important for the successful transition to algebra (Pearn \& Stephens 2015). Thus, a lack of proficiency in fractions is a major contributor to learners' poor performance in mathematics, in general, and algebra, in particular (Thomas 2010). As is evident, knowledge of fractions is an important skill for mathematical achievement, but fractions are also considered as a challenging concept to teach and learn (Ubah \& Bansilal 2018).

To assist in overcoming these challenges, researchers have developed some effective learning strategies to improve learners' understanding of fractions. Recent research on interventions to support learners in their learning of fractions reveals that they have been successful in promoting learners' understanding of fractions by using mnemonic devices and manipulatives with pictures (Amalia et al. 2018). Skosana and Monyai (2013) emphasised that the South African Department of Basic Education is aware that effective teaching may only take place in a supportive learning environment that provides learners with quality learning opportunities.

\section{Exploring the use of technology-based tools in mathematics classrooms}

Rasanen et al. (2019) maintain that even though there is still a debate on the effectiveness of using educational technologies, the use of technology-enhanced teaching and learning for mathematics is progressing swiftly as the technology-based educational tools become more affordable. At the same time, the rise in controlled intervention studies of using technology to support learners with learning difficulties is offering new possibilities to understand the complexities of teaching and learning mathematics. Also, Pope and Mayorga (2019) claimed that there are a plethora of websites and an increasing number of technology-based educational applications that may have an impact on learners' learning and achievement in mathematics. Along similar lines, research (Cheung \& Slavin 2011) has revealed that learner performance in mathematics is enhanced when using technology-based tools.

For supporting the teaching and learning of fractions, using technology-based tools has demonstrated the ability to scaffold the conceptual understanding of fractions (Way 2011). In addition, using technology-based simulations motivates learners and scaffolds their understanding of concepts within fractions in mathematics (Hensberry, Moore \& Perkins 2015). Moreover, using technology-based tools in teaching and learning of mathematics encourages a deeper conceptual understanding of knowledge of fractions compared with traditional teaching and learning methods (Reinhold et al. 2020). 
In keeping with these notions, many education institutions are moving to more mobile and contemporary digital technologies such as tablet computers, laptops and netbooks (Johnson et al. 2016). Also, social media and collaborative platforms such as Google Drive, Google Classroom and Google Docs are being used (Zhou, Simpson \& Domizi 2012). However, for the teacher to choose the appropriate technology-based tool from the plethora of currently available technology-based tools is challenging (Johnson et al. 2016). The idea is to select the best technology-based tool, which will allow teachers to exploit the potential of the available technology to advance learners' learning. However, although technology has been useful for the teaching and learning of mathematics, there are also challenges associated with using technology apart from the ready availability of technology-based tools (Johnson et al. 2016). The successful use of technolgy-based tools is dependant on the design of the tool as well as the activities that need to be interconnected (Drijvers 2013). In addition, teachers and learners ought to socially interact within the classroom context to ascertain, which technology-based tool is the most suitable when teaching and learning mathematics, in general, and fractions, in particular. The teacher can also discuss the design of activities in collaboration with the learner as was the case in the study under focus. Besides, a socio-constructivist approach to teaching and learning enhances learner collaboration, engagement and the sharing of ideas within mathematics classrooms, which may lead to the improvement of learning opportunities for learners (Naude \& Meier 2019).

\section{Exploring notions of social constructivism}

This study was framed by the theory of social constructivism. According to Vygotsky (1978), knowledge is constructed in part by exchanging dialogues and interacting with others within a social environment, as well as the artefacts and tools that mediate learning semiotically. Significant learning occurs through social interaction with teachers and peers (Finnegan \& Ginty 2019). In essence, the classroom is a social setting where interaction is common between learners and teachers, and amongst learners themselves. Views of social constructivists propose that knowledge construction is socially oriented (Ndlovu 2013; Weinberger et al. 2005). These views of social constructivism are supported by Vygotsky (1978) who claims that the difference between learners who are not of the same age intellectually is related to the Zone of Proximal Development (ZPD), which is important for socially constructing knowledge (Eun 2017). The ZPD refers to what learners can do without assistance and what learners may achieve with the support and guidance of a more knowledgeable other (e.g. a friend, peer or teacher). Vygotsky (1978) proposes that the ZPD:

$[\ldots I] \mathrm{s}$ the distance between the actual development level as determined by independent problem solving and the level of potential development as determined through problem solving under adult guidance or in collaboration with more capable peers. (p. 86)
Thus, the teacher needs to acknowledge that when learning new knowledge or skills, learners may require assistance to understand this new information (Clapper 2015; Turuk 2008). This assistance may be provided by the teacher or peers, along similar lines, and this study was guided by the ideas of the ZPD, whereby learners engaged in interactive discussions with their peers and the teacher to support the development of learners' skills and knowledge when solving questions involving fractions. This was seen as a way to scaffold learners' learning. Colter and Ulatowski (2017) claim that scaffolding can be viewed as a transitory form of supported learning, involving discussions and collaboration between the peers and the teacher and learner, to encourage independent learning by the learner.

Graven (2015:2) maintained that 'mathematics learning is considered a social activity in which learners actively construct meaning'. This implies that the social environment in which learners acquire knowledge about mathematics may influence their progress in the learning of concepts in mathematics. Furthermore, in a social constructivist learning environment, there is an expectation of learners' involvement in learning, for example, through using discussion, argument, exchanging of ideas and collaboratively solving realworld problems. In these educational environments, teachers plan and make the learning context available to assist with the learning activities (Richards 2005). In mathematics classrooms, learners socially construct meaning (Graven 2015); thus, during the lessons, the teacher needs to provide learners with the opportunity to engage socially in groups as they solve problems. By so doing, learners may be able to assist and support each other if some members of the group encounter problems with understanding concepts within mathematics. As this study focussed on the use of group work, group discussions and technology-based tools as an instructional strategy when teaching and learning fractions in mathematics, this study aligns itself appropriately with the theory of social constructivism.

Thus, to better understand the perceptions of Grade 5 learners about the use of technology-based tools (i.e. videos and PowerPoint presentations) when learning fractions, this study was grounded on the principles of social constructivism. The ideas of the ZPD were reinforced whereby learners were arranged into smaller groups to complete a task-based worksheet. Each group consisted of learners with diverse learning abilities. The interaction amongst the learners in the group included questioning each other and supporting each other, with discovering answers to the questions posed in the task-based worksheet. This interaction created the opportunity for learners and the teacher to appropriately scaffold and guide other learners collaboratively. Subsequently, learners were then invited to complete a second task-based worksheet after they viewed PowerPoint presentations, which incorporated videos based on the teaching and learning of concepts that were initially taught by using the traditional 'chalk and talk' method. 


\section{Research methods and design}

The interpretive paradigm was used in this study as the interpretive paradigm is concerned with understanding the world based on an interpretation of learners' experiences and perceptions of the world (Dean 2018). Also, Gunbayi and Sorm (2018) indicate that the interpretive paradigm is effective in guiding qualitative research. This study lent itself to the interpretive paradigm as it involved exploring the perceptions of Grade 5 learners. They were learning fractions in mathematics by using technology-based tools (i.e. videos and PowerPoint presentations). The interpretive paradigm provides researchers with the opportunity to understand and interpret the experiences of research participants (Alase 2017). Also, the qualitative research design served as a guide that connected the interpretive paradigm to the data generation methods (Ngozwana 2018).

\section{The pilot study}

A pilot study was conducted with one class of Grade 5 learners $(N=45)$ to refine the research process and research instruments. The validity and reliability of the research process and research instruments were confirmed accordingly. It was important to ensure that the research process and research instruments responded to the key question of the study: What are Grade 5 learners' perceptions of the use of technology-based tools (i.e. videos and PowerPoint presentations) when learning fractions in mathematics? Based on the pilot study, the PowerPoint presentations needed to be refined further so that the concepts being discussed during the PowerPoint presentations were aligned to what was taught by using the initial traditional 'chalk and talk' method. Moreover, the task-based worksheets were revised to align more closely with what was being discussed during the regular 'chalk and talk' lessons and the lessons supported by technology-based tools. Finally, the focus group interview questions were reworked so that the language used was clear and unambiguous.

\section{The main study}

The main study was conducted in the second class of Grade 5 learners $(N=48)$. Data were generated from information that was obtained from two task-based worksheets (Appendices 1 and 2) and focus group interviews. Owing to various reasons, only 40 learners (together with parental permission) agreed to participate in the focus group interviews for the main study.

\section{The traditional 'chalk and talk' teaching method}

A traditional 'chalk and talk' lesson refers to a lesson that is generally teacher centred, where the teacher uses a chalkboard, blackboard or whiteboard to explain concepts, and there is little or no innovative instruction (Maycock 2019). The teaching and learning of concepts in fractions commenced with the entire class of Grade 5 learners $(N=48)$. The traditional 'chalk and talk' lessons focussed on the teaching and learning of fractions, which encompassed the following: counting forwards and backwards, addition and subtraction of fraction with mixed numbers, fractions involving whole numbers, solving problems in real-world contexts involving common fractions, and recognising and using equivalent forms of fractions with denominators that are multiples of each other. These were compulsory concepts that ought to be covered within the Grade 5 curriculum as stipulated by the CAPS document. After the traditional 'chalk and talk' lessons, the learners were asked to complete the first task-based worksheet.

\section{The task-based worksheets}

Whilst working in class on the task-based worksheets (see Appendices 1 and 2), the participants were divided into groups of four to complete each task-based worksheet. Learners were provided with the opportunity to group themselves voluntarily. This was performed with the intention that learners would be more comfortable with their friends and would most probably interact more freely in discussions. These 12 groups of four learners each $(N=48)$ worked collaboratively on completing the task-based worksheets. Although learners worked collaboratively in groups, each learner answered and submitted an individual task-based worksheet.

The worksheets (see Appendices 1 and 2) included content that was taught during the traditional 'chalk and talk' method. Both worksheets were similar regarding the types of questions and the content covered. The administration of the first task-based worksheet followed lessons focussing on the teaching of the various aspects of the fractions curriculum by the teacher/researcher by using the traditional 'chalk and talk' method. Learners worked in groups whilst completing the worksheet, also making use of visual manipulatives in the form of paper folding, diagrams and drawings simultaneously. The use of diagrams and manipulatives (paper folding) also provided a means of scaffolding for learners. The second task-based worksheet commenced approximately 4 weeks after the learners completed the first one. Initially, the traditional 'chalk and talk' method was limited to the use of the textbook, chalkboard, diagrams and manipulatives in the classroom. Thus, the introduction of technology-based tools was an innovative strategy to support learners in their learning of fractions in mathematics. The use of the videos and PowerPoints in this study supported the idea of embracing the notion of the 4IR in the teaching and learning of fractions. The learners completed the second taskbased worksheet in groups immediately after the lessons focussing on the use of two videos and two PowerPoint presentations were completed.

\section{The technology-based tools}

In this study, a compact projector was used as a technologybased tool to enhance the teaching and learning of fractions in mathematics within the era of the 4IR. Learners viewed two PowerPoint presentations of lessons on fractions after answering the first task-based worksheet. The PowerPoint 
presentations included diagrams, pictures and two videos on teaching and learning of concepts within fractions. The concepts of fractions that were incorporated into the two videos included, for example, addition and subtraction of fractions, comparing and ordering of fractions, equivalent forms of fractions, solving of fraction problems in real-world contexts and so on. Thus, these technology-based lessons focussed on a recap of fraction concepts that were initially taught by using the traditional 'chalk and talk' method. The use of technology-based tools within the mathematics classroom supported the notions of teaching and learning within the 4IR. These were collaborative lessons whereby learners could ask questions, and the teacher was able to offer explanations as the lessons and technology-based presentations unfolded. Groups discussed and interacted with each other, which promoted clarification and understanding. Thus, learners' understanding of concepts within fractions was scaffolded by their teacher and peers (More Knowledgeable Other [MKO]) (Clapper 2015).

\section{The focus group interviews}

The participation of learners in the focus group interview was voluntary and based on written consent from both parents and learners. For the focus group interview, 40 of the 48 learners agreed to participate in the interview. These participants were divided into eight groups of five learners each $(N=40)$. The participants agreed to the audio recording of the interviews. The focus group interviews were guided by a series of open-ended questions by using a semistructured focus-group interview schedule. The focus group interviews with the learners served as an appropriate research instrument to generate rich data. Focus group interviews were conducted after learners had completed the second task-based worksheet.

\section{Data analysis}

The qualitative data for this study, which were generated from the participating learners, proved to be effective in responding to the key research question for this study: What are Grade 5 learners' perceptions of the use of technologybased tools (i.e. two videos and two PowerPoint presentations) when learning fractions in mathematics? The audio-recorded focus group interviews stimulated fluent data, which were interrogated to draw out common codes for this study. The audio-recorded focus group interview data were transcribed and read so that common codes could be initially identified. These codes were then carefully perused to refine initial codes into main themes. Responses of the learners to questions for the focus group interviews and the task-based worksheets were used to assimilate information that would contribute towards answering the key research question. Moreover, data analysis in the form of coding and categorising of themes was based on the conceptual framework of the study, that is the theory of social constructivism.

Data analysis included the following steps: acquaintance with the data to identify codes after reading and rereading the qualitative data, arranging sections of the data that were related to each other and studying the data excerpts to warrant that the focus group excerpts revealed a connection and refining the identified codes into themes. Also, member checking was completed to confirm the accuracy of the results and to provide participants with the chance to correct and make additions to the data generated. A detailed discussion focussing on the results of this study may be found in the section that follows.

\section{Ethical consideration}

This study was conducted with one class of Grade 5 learners at one primary school in KwaZulu-Natal, South Africa. Gatekeeper access was obtained from the KwaZulu-Natal Department of Basic Education to conduct research at the school. Also, gatekeeper access was obtained from the research office at the participating university in KwaZuluNatal. The principal of the school, the learners and their parents for the main and pilot study were provided with informed consent forms detailing the processes of the research study.

\section{Results and discussion}

The results of this study are concerned with the thematic analysis and discussion of data generated from the two taskbased worksheets and eight focus group interviews with five learners each. Herzog, Handke and Hitters (2019) describe thematic analysis as consisting of the analytical construction of codes, themes, patterns, evaluation or associations within these themes. Thematic analysis is particularly suitable for analysing experiences, perceptions and understandings and may integrate data of multiple kinds. Therefore, thematic analysis was well suited as a method of analysing the data generated for this research study. In response to the research question: what are the perceptions of Grade 5 learners about the use of technology-based tools (i.e. videos and PowerPoint presentations) when learning fractions in mathematics, two main themes were identified. These themes are that the use of technology-based tools inspired an appealing and fun way of learning fractions and an encouraging atmosphere for learning fractions. In the following section, both themes are discussed in detail.

\section{The use of technology-based tools inspired an appealing and fun way of learning fractions}

For most learners, at the primary school level, the topic fractions in mathematics is challenging (Beilstein 2019; Ubah \& Bansilal 2018). Moreover, promoting learners' development in fractions is critical for their success in other areas of mathematics (Pearn \& Stephens 2015; Thomas 2010).

During the focus group interview sessions in this study, learners were adamant that the introduction of technology into the mathematics lessons had changed their perspective on the learning of fractions to one of fun and enjoyment. When asked about their perceptions of the videos and PowerPoint presentations, the enjoyment and 
fun aspects to learning fractions were cited by many participants. Using the technology-based tools, learners seemed to discover a lighter side to learning mathematics, which would assist in alleviating the notions of anxiety about mathematics, which many learners experience. The aspects of fun are captured in the learners' views, which are expressed in the following focus-group interview excerpts:

Akhona': '... yes it [the videos and PowerPoints] made me learn ... and it was fun too ....' (FG'23, female)

Luke: '... it's much better than doing mathematics in class like we do every time [using the traditional 'chalk and talk' method] ....' (FG4, male)

Sakhile: '... it's easier now ... [referring to fractions that were being explained in the video].' (FG6, male)

Siba: ' $\ldots$ it reminds me about the movies we watch ... it makes you learn ... it's interesting and fun ...' (FG5, female)

Susan: ' $\ldots$ at first I thought that fractions were hard, but then our teacher showed us this movie about fractions ... I think that fractions are easy and fun. I understand ... numerator and denominator ... after the PowerPoint presentations ...' (FG1, female)

From the interview responses, it was evident that learners found the learning of fractions using the PowerPoint presentations, which included videos, fun. This fun aspect to the lesson encouraged the learners to learn. Similarly, Fahmi, Priwantoro and Cahdriyana (2018) suggested that technology may be used to illustrate graphics, videos and audios to enhance the learning of mathematics. As was evident from the interview transcripts, the teaching and learning of fractions were enhanced through using the technology-based tool, that is the PowerPoint presentations. These notions are also evident when comparing the responses with the taskbased worksheets as follows.

As was evident from the data generated in this study, the use of technology-based tools within teaching and learning can be of benefit for learners who have a challenge when learning fractions in mathematics through the traditional 'chalk and talk' method. Similarly, Celik (2018) maintained that if learners find the content and method of teaching for a subject fun and interesting, they actively participate within the classroom. It was evident from this study that the learners collaborated and discussed questions and responses to the task-based worksheet. Through these social interactions, learners actively participated in the lessons by discussing and clarifying the questions on the task-based questionnaire. Moreover, learners were supported by their MKO, thereby learning collaboratively with their teacher and peers (Turuk 2008) to arrive at the correct responses to the task-based worksheet as was evident from the following transcribed excerpts:

1.Pseudonyms have been used to protect the identity of the participants.

2.FG is the acronym used for Focus Group.

3.Words in square brackets within the focus group interview transcripts have been added by the authors to support the reader's understanding of each transcribed excerpt.
Brian: '... it was a very good video ... it helped us in our worksheet ... we could discuss with our friends ... helped in understanding ...' (FG7, male)

Jane: '... yes ... it is much easier now [the understanding of concepts within fractions] ... after watching the video ... makes it look so easy ...' (FG1, female)

Sifiso: '... the first time we did maths like this [teaching and learning by using PowerPoints and videos] ... most of the time ... maths is hard, but this [the video] helped me ... I could also ask you [the teacher] and the group [learners involved in group work while answering the task-based worksheets] for help ...' (FG6, male)

As was evident from this study, the teaching and learning of mathematics were supported by using the technology-based tools. Along the similar lines, Cheung and Slavin (2011) maintain that learner performance in mathematics is enriched when technology-based tools are used within the classroom for teaching and learning. Moreover, research (Saylan, Onal \& Onal 2018) has shown that the lack of technology-based tools in classrooms affects learners' attitudes, interests, enjoyment and participation within the lessons. Thus, based on the data generated in this study, the teaching and learning within mathematics classrooms would benefit from the use of technology-based tools.

What was also evident from the response of the participants was that to attract learners' attention, methods of teaching and learning ought to be fun as it might be difficult to gain learners' interest once they have lost interest in the lessons. Furthermore, if we attempt to make teaching and learning fun and thought-provoking, this may inspire learners' interest in learning mathematics. Through this added interest, learners may develop a greater appreciation for mathematics and technology (Lee \& Chan 2019), which may lead to an enhancement of reasoning, problem-solving and criticalthinking skills. Encouraging critical thinking and problemsolving in mathematics is essential for the development of successful learners (Lin \& Rosli 2017). Moreover, when learning is fun, learners have an increased probability of remembering the concepts later (Marcut 2005). Thus, when the learning process is addressed as a fun activity, it supports the development of meaningful learning as learners learn best when they are having fun.

\section{The use of technology-based tools inspired an encouraging atmosphere for learning fractions}

The notion that technology-based learning fosters an encouraging atmosphere for the learning of mathematics, in general (Umugiraneza, Bansilal \& North 2018), and fractions, in particular (Suh, Moyer \& Heo 2005), is a recurring theme that manifests itself throughout this study as was evident in the focus group interview excerpts:

Abby: ' ... this was the best mathematics lesson, so I will tell my friends what I saw on the video ...' (FG2, female)

John: '... I loved watching how all the fractions were explained. It was different from how we did fractions before ... [referring to the traditional 'chalk and talk' method].' (FG2, male) 
Larry: '... this is the first time we used a computer for maths ... be fun to do our other subjects like this too ...' (FG4, male)

Lihle: '... yes, I think it is easy because they [the video] explained how to do the sums ... you can understand how to do it now ...' (FG8, female)

Siba: ' ... yes ... I was a bit confused ... but after discussing what we saw in the video with my group ... I understand ...' (FG5, female)

This change in outlook to learning fractions is evident in the preceding excerpts. The learners in this study believed that the use of the technology-based tools in the learning of fractions prompted them to exhibit greater enthusiasm and inspired an encouraging atmosphere for learning mathematics. The creative incorporation of technology into the learning process elevated the regular, passive learning that learners were accustomed to and facilitated collaborative learning with social interaction (Finnegan \& Ginty 2019) and effective mathematical communication.

Furthermore, the introduction of technology into the lessons created a feeling of confidence arising from an appreciation of learners' ability to remember what they have learned. The learners also felt that the use of the technology-based tool scaffolded (Eun 2017) their learning of fractions. These sentiments are reflected in the following transcript excerpts:

Allan: '... yes ... they can help us ... I can remember more ... [referring to the videos and PowerPoint presentations].' (FG4, male)

Ann: '... the videos made me more relieved that I don't have to worry. It taught me more ...' (FG8, female)

Brian: '.. it was a very good video $\ldots$ it helped us in our worksheet ...' (FG7, male)

Nonhle: '... yes ... it's nice to have this group work, and the video ... helps me understand ...' (FG5, female)

Siba: '... I like to see the sums on the screen ... I enjoyed watching ... I understood more now ...' (FG5, female)

Sifiso: '... this was the first time we did maths like this ... most of the time I feel maths is hard, but this [referring to the PowerPoint presentations] helped me ...' (FG6, male)

Thabo: '. .. I couldn't understand it before ... but now I remember after watching the video ...' (FG8, male)

Thus, instead of continuing with the traditional 'chalk and talk' teaching methods, this research study embraced the use of a technology-based tool (the two videos and two PowerPoint presentations) in the classroom. A learning environment was created whereby all learners were able to make use of the videos and PowerPoint presentations to clarify any misunderstandings regarding the content, as well as to use the information that was presented to enhance their learning of fractions. The learners in this study viewed the two PowerPoint presentations and the two videos prior to discussing their meaning making of the fraction concepts they had viewed with the teacher and the other group members. The learners socially interacted (Weinberger et al. 2005) and collaborated within their groups and with the teacher to clarify any confusion to promote meaningful learning and advance their mathematical progress (Graven 2015).

As we are living within the era of the 4IR, there is a need for learners to transform their thinking to be successful within this technologically advanced period (Leneway 2018). In this study, as learners completed the second task-based worksheet, they were able to reflect on the videos and PowerPoint presentations that had been used to amplify and support their learning of fractions. As learners reflected on the use of the videos and PowerPoint presentations, the teacher encouraged collaborative discussions, focussing on the fraction concepts that were being taught. With an enhanced understanding of fractions facilitated by using videos, PowerPoint presentations and interactive discussion, it was more likely that learners would be able to remember and recall what they had learnt. It was evident from the data generated that learners were able to answer more questions correctly in the second task-based worksheet. A few examples of the difference in learners' responses to questions in the first and second task-based worksheets are presented in Figures 3-5.

The example shown in F within Figure 3 provides evidence of the reorganisation in Nancy's reasoning with how she solved a related question in the first task-based worksheet. Nancy seemed to have achieved clarity on the question linked to fractions on a number line in the second task-based

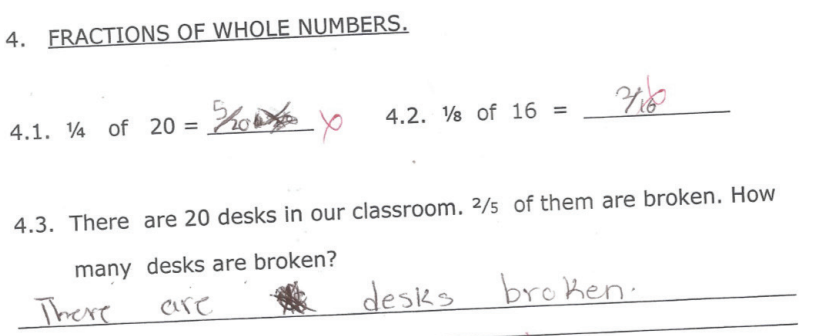

Question4: Fractions of Whole Numbers.

4.1. Solve the following.

a. $1 / 4$ of $44=11$ b. $1 / 8$ of $48=$

c. There are 100 learners in grade 5 . Three quarters of them come to school by bus. How many children come by bus?

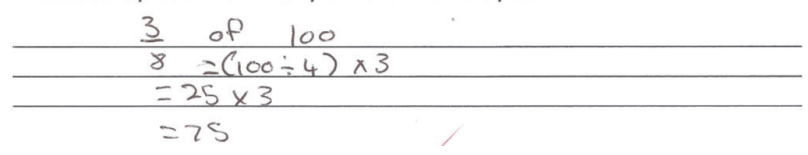

B: Kim's response to the question on fractions of whole numbers in the second task-based worksheet.

FIGURE 1: An example of Kim's responses to the task-based worksheets. 
2. EQUIVALENT FRACTIONS.

Use the diagram below to write the equivalent fraction for.

\begin{tabular}{|c|c|c|c|c|c|c|c|}
\hline \multicolumn{8}{|c|}{1 WHOLE } \\
\hline \multicolumn{4}{|c|}{$1 / 2$} & \multicolumn{4}{|c|}{$1 / 2$} \\
\hline \multicolumn{2}{|c|}{$1 / 4$} & \multicolumn{2}{|c|}{$1 / 4$} & \multicolumn{2}{|c|}{$1 / 4$} & \multicolumn{2}{|c|}{$1 / 4$} \\
\hline $1 / 8$ & $1 / 8$ & $1 / 8$ & $1 / 8$ & $1 / 8$ & $1 / 8$ & $1 / 8$ & $1 / 8$ \\
\hline
\end{tabular}

2.1. $1 / 4=2^{2 / 4}$

2.2. $4 / 8=S S / 6$

C: Sakhile's response to the question on equivalent fractions in the first task-based worksheet.

Question 2: Equivalent Fractions.

2.1. Use the diagram below to write the equivalent fraction for.

\begin{tabular}{|c|c|c|c|c|c|c|c|}
\hline \multicolumn{8}{|c|}{1 WHOLE } \\
\hline \multicolumn{3}{|c|}{$1 / 2$} & \multicolumn{4}{c|}{$1 / 2$} \\
\hline \multicolumn{2}{|c|}{$1 / 4$} & \multicolumn{2}{|c|}{$1 / 4$} & \multicolumn{2}{|c|}{$1 / 4$} & $1 / 8$ & $1 / 8$ \\
\hline $1 / 8$ & $1 / 8$ & $1 / 8$ & $1 / 8$ & $1 / 8$ & $1 / 8$ & $1 / 8$ & 1 \\
\hline
\end{tabular}

$$
\text { a. } 1 / 2=2 / 4 \quad \text { b. } 3 / 4=4 / 4
$$

2.2. Use the above diagram and fill in $\langle$, > or $=$.
a. ${ }_{4 / 8}{ }_{2 / 4}$
b. $4 / 4 \sum 7 / 8$

D: Sakhile's response to the question on equivalent fractions in the second task-based worksheet.

FIGURE 2: An example of Sakhile's responses to the task-based worksheets.

1.2. Circle the mistakes on this number line and write the correct answer underneath.

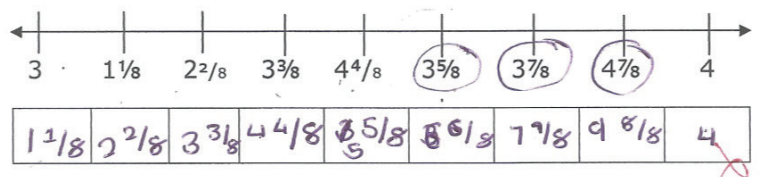

E: Nancy's response to the question on number lines in the first task-based worksheet.

1.2. Complete labelling the number line below by filling in the fractions

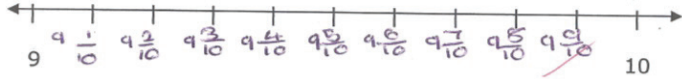

F: Nancy's response to a question on number lines in the second task-based worksheet.

FIGURE 3: An example of Nancy's responses to both the first and second task-based worksheets.

worksheet after viewing the videos within the PowerPoint presentations.

Similarly, Thabo's solution to the question on fractions of whole numbers ( $\mathrm{H}$ within Figure 4 ) provides evidence that the incorporation of technology-based tools within the lessons on fractions contributed positively in assisting him to gain a better understanding of concepts within fractions. This was also evident from Nonhle's responses in the focus

\section{FRACTIONS OF WHOLE NUMBERS.

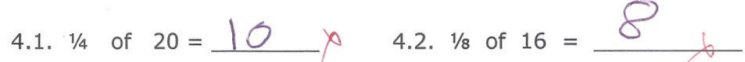 \\ 4.3. There are 20 desks in our classroom. $2 / 5$ of them are broken. How many desks are broken? 18

率

G: Thabo's response to the question on fractions of whole numbers in the first task-based worksheet.

Question4: Fractions of Whole Numbers.

4.1. Solve the following.

a. $1 / 4$ of $44=$ b. $1 / 1 / 8$ of $48=6$

c. There are 100 learners in grade 5. Three quarters of them come to

school by bus. How many children come by bus?

$(100 \div 4) \times 3$

$=25 \times 9$

\section{$-75$}

$\mathrm{H}$ : Thabo's response to a question relating to fractions of whole numbers in the second task-based worksheet.

FIGURE 4: An example of Thabo's responses to both the first and second task-based worksheets.

group interview, as well as from her answer to the question focussing on equivalent fractions in the second task-based worksheet (J within Figure 5) that follows.

What was evident from the focus group interview as well as from the responses on the second task-based worksheet was that the participating learners valued and embraced the use of the technology-based tools in the classroom. It was also evident from the responses to the second taskbased worksheet (see Figures 1-5) and the focus group interviews that the use of the technology-based tools supported the learners' understanding of the mathematics being taught (Cheung \& Slavin 2011). This understanding promoted an encouraging atmosphere to work within, and prompted social interaction and discussion to clarify the concepts being taught (Naude \& Meier 2019). This created a socio-constructive atmosphere within the classroom under study, which promoted teaching and learning.

\section{Conclusion}

Researchers, teachers, teacher educators and policymakers have been exploring innovative ways to integrate technology in classrooms to enhance teaching and learning. Thus, with a view to transforming teaching and learning in a South African mathematics classroom within the era of the 4IR, this study sought to explore Grade 5 learners' perceptions of learning fractions in mathematics by using technology-based tools (i.e. videos and PowerPoint presentations). 


\section{EQUTVALENT FRACTIONS.}

Use the diagram below to write the equivalent fraction for.

\begin{tabular}{|c|c|c|c|c|c|c|c|}
\hline \multicolumn{8}{|c|}{1 WHOLE } \\
\hline \multicolumn{7}{|c|}{$1 / 2$} & \multicolumn{4}{|c|}{$1 / 2$} \\
\hline \multicolumn{2}{|c|}{$1 / 1 / 4$} & \multicolumn{2}{|c|}{$1 / 4$} & $1 / 4$ & $1 / 8$ & $1 / 8$ \\
\hline $1 / 8$ & $1 / 8$ & $1 / 8$ & $1 / 8$ & $1 / 8$ & $1 / 8$ & $1 / 4$ \\
\hline
\end{tabular}

$2.1 .1 / 4=214 \quad 0 \quad 2.2 .4 / 8=X$

I: Nonhle's response to the question on equivalent fractions in the first task-based worksheet.

Question 2: Equivalent Fractions.

2.1. Use the diagram below to write the equivalent fraction for.

\begin{tabular}{|c|c|c|c|c|c|c|c|}
\hline \multicolumn{8}{|c|}{1 WHOLE } \\
\hline \multicolumn{3}{|c|}{$1 / 2$} & \multicolumn{4}{c|}{$1 / 2$} \\
\hline \multicolumn{2}{|c|}{$1 / 4$} & \multicolumn{2}{|c|}{$1 / 4$} & \multicolumn{2}{c|}{$1 / 4$} & \multicolumn{2}{c|}{$1 / 4$} \\
\hline $1 / 8$ & $1 / 8$ & $1 / 8$ & $1 / 8$ & $1 / 8$ & $1 / 8$ & $1 / 8$ \\
\hline
\end{tabular}

$$
\text { a. } 1 / 2=\frac{4}{8} / \frac{2}{9} \quad \text { i } \text { b. } 3 / 4=\frac{6}{8}
$$

2.2. Use the above diagram and fill in $\stackrel{5}{<},\rangle_{\text {or }}=$.

a. $4 / 8=2 / 4$

$$
\text { b. } 4 / 4>7 / 8
$$

J: Nonhle's response to the question on equivalent fractions in the second task-based worksheet.

FIGURE 5: An example of Nonhle's responses to both the first and second task-based worksheets.

The qualitative, interpretive analysis of the focus group interviews and responses to the task-based worksheets revealed two main results. Firstly, the use of technologybased tools inspired an appealing and fun way of learning fractions. Additionally, the use of technology to learn fractions resolved the confusion around the concepts and terminology associated with learning fractions and brought out fun and enjoyment in the learning of mathematics. Secondly, the use of technology-based tools inspired an encouraging atmosphere for learning fractions. Moreover, the use of technology-based tools motivated learners to interact and participate in the mathematics lessons socially. The findings of this study have revealed that learners are encouraged to participate actively in mathematics lessons that are enjoyable and interesting. This motivation can lead to improved learner performance in mathematics.

Moreover, at the research site where this study was conducted, the resources that are generally used for teaching and learning are the chalkboard, textbooks, worksheets and workbooks. The integration of technology as a teaching tool was a new experience for the participating learners. Based on the researchers' observations, before the lesson, the learners were excited to see the projector and laptop being connected. Learners enthusiastically awaited what would be projected on the screen. The participating learners' interest was stimulated, and their attention was focussed on the content being presented. Discipline and classroom management were also good during the lesson. This was novel, because based on the researchers' observations and experiences, during other mathematics lessons it was often a challenge to obtain the undivided attention of learners because there is a large number of learners in the class and they were easily distracted. Based on the evident enthusiasm and the participating learners' deep interest in the technology-based lessons, this culminated in an enhanced understanding of the concepts within fractions. This heightened understanding of the concepts under study was evident from the participating learners' responses to the second task-based worksheet as depicted in the Results and Discussion section of this article.

The analysis of data generated from this study also suggested that the participating learners embraced the use of videos and PowerPoint presentations to facilitate the successful learning of fractions in mathematics. This study exhibited that if teachers globally aspire to prepare learners with the skills necessary to be successful within the era of the 4IR, then the knowledge of and the ability to use technology-based tools within the classroom is essential. Integrating discussions and collaborative learning by using technology-based tools is important for successful teaching and learning and is necessary for preparing learners for the future. This preparation can educate mathematics learners to participate at an advanced global level. Moreover, within the current context of the global coronavirus disease 2019 (COVID-19) pandemic, educational institutions globally are embracing remote and online teaching and learning. Within the ambit of online teaching and learning, the use of technology-based tools is essential. Thus, within the COVID-19 pandemic era, integrating technology-based tools within pedagogy is important for successful teaching and learning. Therefore, if teachers embrace the use of technology-based tools for teaching and learning, learners will be better prepared to learn and succeed in online educational environments.

The limitations of this study were that this was a small qualitative study conducted with one class of Grade 5 learners within one school in KwaZulu-Natal, South Africa. Opportunities for future research could include studies conducted at several schools within different provinces in South Africa. This study could also be accomplished with primary schools internationally. Large-scale data may provide greater statistical consistency and better opportunities for further quantitative and qualitative analysis and interpretation.

\section{Acknowledgements}

The authors are grateful to the National Research Foundation (NRF) who partially funded this research study. 


\section{Competing interests}

The authors have declared that no competing interests exist.

\section{Authors' contributions}

All authors contributed equally to this work.

\section{Funding information}

The National Research Foundation (NRF) partially funded this research study (NRF Grant Number: TTK170408226284, UID: 113952).

\section{Data availability statement}

Data are available from the corresponding author on request.

\section{Disclaimer}

The views and opinions expressed in this article are those of the authors and do not necessarily reflect the official policy or position of any affiliated agency of the authors.

\section{References}

Alase, A., 2017, 'The interpretative phenomenological analysis (IPA): A guide to a good qualitative research approach', International Journal of Education and Literacy Studies 5(2), 9-19. https://doi.org/10.7575/aiac.ijels.v.5n.2p.9

Amalia, R., Saiman, S., Sofiyan, S. \& Mursalin, M., 2018, 'Designing computer-based fraction worksheets for junior high school', in IOP Conference Series: Journal of Physics: The 6th South East Asia Design Research International Conference (6th Physics: The 6th South East Asia Design Research International Conference (6th
SEA-DR IC), Conference Series 1088 (012110), pp. 1-8, Banda Aceh, June 27-28, 2018.

Beilstein, S.O., 2019, 'Supporting children's conceptual understanding of fractions with manipulatives and gesture', PhD thesis, Department of Education Psychology, University of Illinois, Champaign.

Bruce, C.D., 2012, Technology in the mathematics classroom: Harnessing the learning potential of interactive whiteboards, What works? Research into Practice 38 , pp. 1-4, Ontario Association of Deans of Education, Ontario.

Celik, H.C., 2018, 'The effects of activity-based learning on sixth-grade students' achievement and attitudes towards mathematics activities', EURASIA Journal of Mathematics, Science and Techr
org/10.29333/ejmste/85807

Chen, B., 2015, 'Exploring the digital divide: The use of digital technologies in Ontario public schools', Canadian Journal of Learning and Technology 40(3), 1-22. https:// doi.org/10.21432/T2KP6F

Cheung, A.C.K. \& Slavin, R.E., 2011, 'The effectiveness of educational technology applications for enhancing mathematics achievement in K-12 classrooms: A metaanalysis', Educational Research Review 9(1), 88-113. https://doi.org/10.1016/ j.edurev.2013.01.001

Clapper, T.C., 2015, 'Cooperative-based learning and the zone of proximal development', Simulation and Gaming 46(2), 148-158. https://doi. org/10.1177/1046878115569044

Colter, R. \& Ulatowski, J., 2017, 'The unexamined student is not worth teaching: Preparation, the Zone of Proximal Development, and the Socratic Model of Scaffolded learning', Educational Philosophy and Theory 49(14), 1367-1380. https://doi.org/10.1080/00131857.2017.1282340

Dean, B.A., 2018, 'The interpretivist and the learner', International Journal of Doctoral Studies 13(1), 1-8. https://doi.org/10.28945/3936

Department of Basic Education, 2011, Curriculum and Assessment Policy Statement (CAPS), Mathematics, Department of Basic Education, Pretoria

Drijvers, P., 2013, 'Digital technology in mathematics education: Why it works (or doesn't)', PNA 8(1), 1-20. https://doi.org/10.1007/978-3-319-17187-6_8

Eun, B., 2017, 'The zone of proximal development as an overarching concept: A framework for synthesising Vygotsky's theories', Educational Philosophy and Theory 51(1), 18-30. https://doi.org/10.1080/00131857.2017.1421941

Fahmi, S., Priwantoro, S. \& Cahdriyana, R.A., 2018, 'Development and effectiveness of interactive learning media for mathematical logic and set towards students' selfconfidence on computer', International Journal of Engineering and Technology 7(4), 96-99. https://doi.org/10.14419/ijet.v7i4.30.22027

Fennell, F. \& Karp, K., 2017, 'Fraction sense: Foundational understandings', Journal of Learning Disabilities 50(6), 648-650. https://doi.org/10.1177/0022219416662030

Finnegan, M. \& Ginty, C., 2019, 'Moodle and social constructivism: Is Moodle being used as constructed? A case study analysis of Moodle use in teaching and learning in an Irish Higher Educational Institute', All Ireland Journal of Teaching and Learning in Higher Education 11(1), 1-21.
Graven, M., 2015, 'Strengthening maths learning dispositions through "math clubs"', South African Journal of Childhood Education 5(3), 1-7. https://doi.org/10.4102/ South African
sajce.v5i3.342

Gunbayi, I. \& Sorm, S., 2018, 'Social paradigms in guiding social research design: The functional, interpretive, radical humanist and radical structural paradigms', International Journal on New Trends in Education and Their Implications 9(2), 57-76.

Hensberry, K.K.R., Moore, E.B. \& Perkins, K., 2015, 'Using technology effectively to teach about fractions', Australian Primary Mathematics Classroom 20(4), 19-25.

Herzog, C., Handke, C. \& Hitters, E., 2019, 'Analysing talk and text II: Thematic analysis', in H. Van den Bulck, M. Puppis, K. Donders \& L. Van Audenhove (eds.), The Palgrave handbook of methods for media policy research, pp. 385-401, Palgrave Macmillan, London.

Johnson, A.M., Jacovina, M.E., Russell, D.E. \& Soto, C.M., 2016, 'Challenges and solutions when using technologies in the classroom', in S.A. Crossley \& D.S. McNamara (eds.), Adaptive educational technologies for literacy instruction pp.13-29, Taylor \& Francis, New York, NY.

Kaplan, R.G. \& Alon, S., 2013, 'Using technology to teach equivalence', Teaching Children Mathematics 19(1), 382-389. https://doi.org/10.5951/teacchilmath 19.6.0382

Kurniawan, H., Sutawidjaja, A., As'ari, A.R. \& Muksar, M., 2018, 'The thinking process of students in representing images to symbols in fractions', in Journal of Physics: Conference Series, 1028 (012138), 2nd international conference on statistics, mathematics, teaching, and research, pp. 1-7, Makassar, October 9-10, 2017.

Lee, C.S. \& Chan, P.Y., 2019, 'Mathematics learning: Perceptions toward the design of a website based on a fun computational thinking-based knowledge management framework', in S.C. Kong \& H. Abelson (eds.), Computational thinking education, pp. 183-200, Springer, Singapore. https://doi.org/10.1007/978-981-13-6528-7_11

Leneway, R.J., 2018, Transforming K-12 classrooms with digital technology: A look at what works! Western Michigan University, Kalamazoo.

Lin, T.W. \& Rosli, R., 2017, 'Rural school students' perception about learning Mathematics in English', Research Journal of Applied Sciences 12(1), 148-156.

Loc, N.P., Tong, D.H. \& Chau, P.T., 2017, "Identifying the concept "fraction" of primary school students: The investigation in Vietnam', Educational Research and Reviews 12(8), 531-539. https://doi.org/10.5897/ERR2017.3220

Marcut, I., 2005, 'Critical thinking applied to the methodology of teaching mathematics', Educat, ia Matematic 'a 1(1), 57-66.

Maycock, K.W., 2019, 'Chalk and talk versus flipped learning: A case study', Journal of Computer Assisted Learning 35 (1), 121-126. https://doi.org/10.1111/jcal.12317

Mullis, I.V.S., Martin, M.O. \& Sainsbury, M., 2015, 'PIRLS 2016 reading framework', in I.V.S. Mullis \& M.O. Martin (eds.), PIRLS 2016 Assessment Framework, 2 nd edn., pp. 11-29, TIMSS \& PIRLS International Student Center, Boston College. Chestnut Hill, MA.

Naude, M. \& Meier, C., 2019, 'Elements of the physical learning environment that impact on the teaching and learning in South African Grade 1 classrooms', South African Journal of Education 39(1), 1-11. https://doi.org/10.15700/saje. v39n1a1342

Ndlovu, M., 2013, 'Revisiting the efficacy of constructivism in mathematics education', Philosophy of Mathematics Education Journal 27(1), 1-13.

Ngozwana, N., 2018, 'Ethical dilemmas in qualitative research methodology: Researcher's reflections', International Journal of Educational Methodology 4(1), 19-28. https://doi.org/10.12973/ijem.4.1.19

Pearn, C. \& Stephens, M., 2015, 'Strategies for solving fraction tasks and their link to algebraic thinking', in M. Marshman, V. Geiger \& A. Bennison (eds.), Mathematics education in the margins, Proceedings of the 38th annual conference of the education in the margins, Proceedings of the 38th annual conference of the
Mathematics Education Research Group of Australasia, pp. 493-500, Mathematics Education Research Group of Australasia, Sunshine Coast.

Pope, S. \& Mayorga, P., 2019, Enriching mathematics in the primary curriculum, Sage, London.

Rasanen, P., Laurillard, D., Käser, T. \& Von Aster, M., 2019, 'Perspectives to technologyenhanced learning and teaching in mathematical learning difficulties', in A. Fritz, V. Haase \& P. Rasanen (eds.), International handbook of mathematical learning difficulties, pp. 733-754, Springer, Cham.

Reinhold, F., Hoch, S., Werner, B., Richter-Gebert, J. \& Reiss, K., 2020, 'Learning fractions with and without educational technology: What matters for highachieving and low-achieving students?', Learning and Instruction 65(1), 1-19. https://doi.org/10.1016/j.learninstruc.2019.101264

Richards, C., 2005, 'The design of effective ICT-supported learning' activities: Exemplary models, changing requirements, and new possibilities', Language Learning and Technology 9(1), 60-79.

Riley, N., Lubans, D.R., Holmes, K., Hansen, V., Gore, J. \& Morgan, P.J., 2017 'Movement-based mathematics: Enjoyment and engagement without compromising learning through the EASY Minds program', Eurasia Journal of Mathematics, Science and Technology Education 13(6), 1653-1673. https://doi. org/10.12973/eurasia.2017.00690a

Saylan, A., Onal, N.T. \& Onal, N., 2018, 'Using technology in education from the preservice science and mathematics teachers' perspectives', International Education Studies 11(10), 28-41. https://doi.org/10.5539/ies.v11n10p28

Sherman, H.J., Richardson, L.I. \& Yard, G.J., 2019, Teaching learners who struggle with mathematics: Responding with systematic intervention and remediation, Pearson Publishers, Waveland Press, Long Grove, Illinois.

Siegler, R.S., Fazio, L.K., Bailey, D.H. \& Zhou, X., 2013, 'Fractions: the new frontier for theories of numerical development', Trends in Cognitive Sciences 17(1), 13-19. https://doi.org/10.1016/j.tics.2012.11.004 
Simon, M.A., Placa, N., Avitzur, A. \& Kara, M., 2018, 'Promoting a concept of fractionas-measure: A study of the learning through activity research programme', The
Journal of Mathematical Behaviour 52(1), 122-133. https://doi.org/10.1016/ Journal of Mathematica

Skosana, P.S. \& Monyai, R.B., 2013, 'Learner-centred policies with reference to constructivism in the implementation of the curriculum', International Journal of Humanities and Social Science Invention 2(9), 51-58.

Spangenberg, E.D., 2017, 'Comparing the achievement goal orientation of mathematics learners with and without attention-deficit hyperactivity', South African Journal of Education 37(3), 1-11. https://doi.org/10.15700/saje. v37n3a1419

Suh, J., Moyer, P.S. \& Heo, H.-J., 2005, 'Examining technology uses in the classroom: Developing fraction sense using virtual manipulative concept tutorials', Journal of Interactive Online Learning 3(4), 1-22.

Thomas, C., 2010, 'Fraction competency and algebra success', Master's thesis, Department of Natural Sciences, Louisiana State University, viewed 18 April 2020 from https://digitalcommons.Isu.edu/gradschool_theses/3578.

Tobin, P.C. \& Weiss, V., 2016, 'Teaching undergraduate mathematics using CAS technology: Issues and prospects', International Journal for Technology in Mathematics Education 23(1), 35-41. https://doi.org/10.1564/tme_v23.1.04

Turuk, M.C., 2008, 'The relevance and implications of Vygotsky's sociocultural theory in the second language classroom', Annual Review of Education, Communication and Language Sciences 5(1), 244-262.
Ubah, J.A.I. \& Bansilal, S., 2018, 'Pre-service primary mathematics teachers' understanding of fractions: An action-process-object-schema perspective', South African Journal of Childhood Education 8(2), 1-12. https://doi.org/10.4102/sajce.v8i2.539

Umugiraneza, O., Bansilal, S. \& North, D., 2018, 'Exploring teachers' use of technology in teaching and learning mathematics in KwaZulu-Natal schools', Pythagoras 39(1), 1-6. https://doi.org/10.4102/pythagoras.v39i1.342

Vygotsky, L.S., 1978, Mind in society: The development of higher psychological processes, Harvard University Press, Cambridge, MA.

Way, J., 2011, 'Developing fraction sense using digital learning objects', in J. Way \& J. Bobis (eds.), Fractions: Teaching for understanding, pp. 153-166, The Australian Association of Mathematics Teachers (AAMT) Inc., Adelaide.

Weinberger, A., Ertl, B., Fischer, F. \& Mandl, H., 2005, 'Epistemic and social scripts in computer-supported collaborative learning', Instructional Science 33(1), 1-30. https://doi.org/10.1007/s11251-004-2322-4

Wijaya, A., 2017, 'The difficulties of Indonesian fourth-graders in learning fractions: An early exploration of TIMSS 2015 results', Paper presented at the 4th International Conference on Research, Implementation and Education of Mathematics and Science (4th ICRIEMS), pp. 050027-1-050027-9, Yogyakarta, May 15-16, 2017.

Zhou, W., Simpson, E. \& Domizi, D.P., 2012, 'Google docs in an out-of-class collaborative writing activity', International Journal of Teaching and Learning in Higher Education 24(3), 359-375, Viewed 08 November 2020, from https://files.eric. ed.gov/fulltext/EJ1000688.pdf. 


\section{Appendix 1: First task-based worksheet: Fractions.}

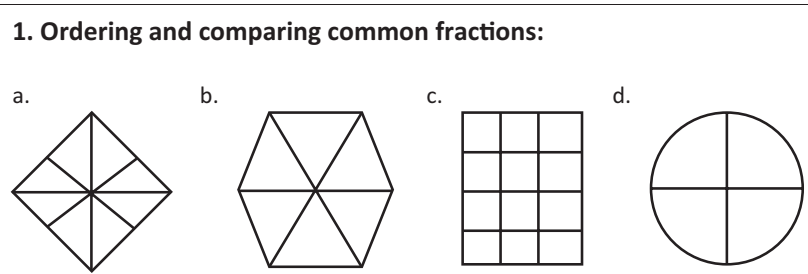

1.1. Identify the fractions represented by the parts in each shape: a.

c.

b.

d.

1.2. Circle the mistakes on this number line and write the correct answer underneath.

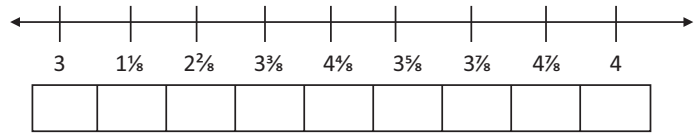

2. Equivalent fractions.

Use the diagram below to write the equivalent fraction for:

\begin{tabular}{|c|c|c|c|c|c|c|c|}
\hline \multicolumn{8}{|c|}{1 WHOLE } \\
\hline \multicolumn{3}{|c|}{$1 / 2$} & \multicolumn{4}{|c|}{$1 / 2$} \\
\hline \multicolumn{2}{|c|}{$1 / 4$} & $1 / 4$ & \multicolumn{2}{|c|}{$1 / 4$} \\
\hline $1 / 8$ & $1 / 8$ & $1 / 8$ & $1 / 8$ & $1 / 8$ & $1 / 8$ & $1 / 8$ & $1 / 8$ \\
\hline
\end{tabular}

2.1. $1 / 4=$

2.2. $4 / 8=$

2.3. Use the above diagram and fill in ‘, > or $=$

a. $1 / 2 \square 3 / 8$

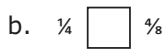

3. Addition and subtraction of fractions

3.1. $8 \frac{5}{8}+2 \frac{1}{8}=$

3.2. $11 \frac{1}{8}-5^{3 / 3}=$

3.3. Dad brings home $5 \frac{3}{8}$ chocolate from work. Mum eats $2 \frac{1}{8}$. How much is left?

4. Fractions of whole numbers.

4.1. $1 / 4$ of $20=$ 4.2. $1 / 8$ of $16=$

4.3. There are 20 desks in our classroom. $2 / 5$ of them are broken. How many desks are broken?

\section{Appendix 2: Second task-based worksheet: Fractions.}

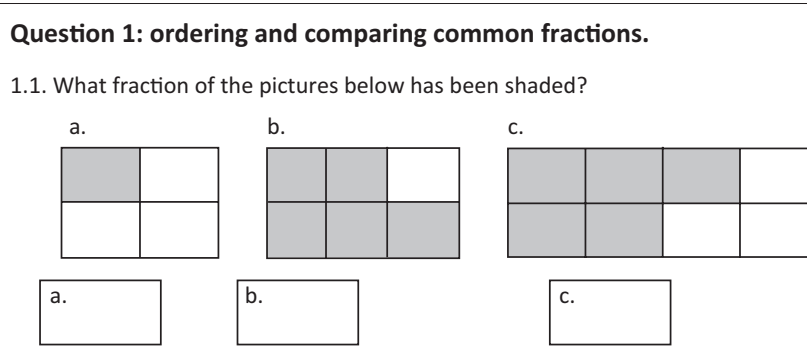

1.2. Complete labelling the number line below by filling in the fractions

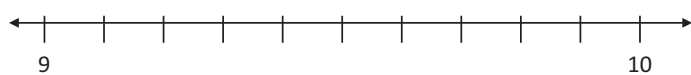

Question 2: equivalent fractions.

2.1. Use the diagram below to write the equivalent fraction for:

\begin{tabular}{|c|c|c|c|c|c|c|c|}
\hline \multicolumn{8}{|c|}{1 WHOLE } \\
\hline \multicolumn{3}{|c|}{$1 / 2$} & \multicolumn{5}{c|}{$1 / 2$} \\
\hline \multicolumn{2}{|c|}{$1 / 4$} & $1 / 1 / 8$ & \multicolumn{3}{|c|}{$1 / 4$} & \multicolumn{3}{c|}{$1 / 4$} \\
\hline $1 / 8$ & $1 / 8$ & $1 / 8$ & $1 / 8$ & $1 / 8$ & $1 / 8$ & $1 / 8$ \\
\hline
\end{tabular}

a. $1 / 2=$

b. $3 / 4=$

2.2. Use the above diagram and fill in <, > or =
a. $4 / 8$
$4 / 8 \square 2 / 4$

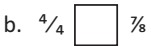

Question 3: addition and subtraction of mixed numbers.

3.1. $54 / 9+73 / 9=$

3.2. $24 \frac{7}{8}-13 \frac{5}{8}=$

3.3. Our family goes out for pizza. My brother brings home $3 / 8$ of his pizza, my sister $4 / 8$, and I bring home $5 / 8$. How much pizza did we bring home altogether?

Question 4: fractions of whole numbers.

4.1. Solve the following.

a. $1 / 4$ of $44=$

c. There are 100 learners in grade 5 . Three-quarters of them come to school by bus. How many children come by bus? 